\title{
Isolation and Characterization of Three New Promoters from Gossypium hirsutum that Show High Activity in Reproductive Tissues
}

\author{
Sinara Artico • Julia Lambret-Frotté • Sarah Muniz Nardeli • \\ Osmundo Brilhante Oliveira-Neto • Maria Fátima Grossi-de-Sa • \\ Marcio Alves-Ferreira
}

Published online: 7 November 2013

(C) Springer Science+Business Media New York 2013

\begin{abstract}
Engineering of plant protection requires wellcharacterized tissue-specific promoters for the targeted expression of insecticidal resistance genes. Herein, we describe the isolation of five different fragments of promoters of three distinct flower-specific cotton (Gossypium hirsutum) genes. Expression analyses of the three genes GhPME-like1, GhßGal-like1 and GhPL-likel revealed that they are expressed highly in flowers buds ranging from 4 to $12 \mathrm{~mm}$ in size. Several putative regulatory cis-elements were identified in the promoter regions, including elements involved in the control of tissue-specific gene expression in pollen grains and fruits. In vivo analyses of these promoters were performed using the heterologous plant system Arabidopsis thaliana by fusing them with the gene uidA (GUS). GUS staining in Arabidopsis tissues revealed that their expression was restricted to anthers, with the majority of expression in pollen grains
\end{abstract}

Electronic supplementary material The online version of this article (doi:10.1007/s11105-013-0674-0) contains supplementary material, which is available to authorized users.

S. Artico · J. Lambret-Frotté $\cdot$ S. M. Nardeli $\cdot$ M. Alves-Ferreira $(\square)$ Department of Genetics, Federal University of Rio de Janeiro (UFRJ), Av. Prof. Rodolpho Paulo Rocco, s/n - Prédio do CCS Instituto de Biologia, $2^{\circ}$ andar, sala A2-93, 219410-970 Rio de Janeiro, RJ, Brazil

e-mail: alvesfer@uol.com.br

S. Artico

e-mail: sinaraartico@gmail.com

J. Lambret-Frotté

e-mail: lambret.julia@gmail.com

S. M. Nardeli

e-mail: snardeli@gmail.com and in the upper portion of the carpels and siliques. A comparison between a CaMV35S::GUS constitutive promoter and the promoters isolated in this study revealed that the cotton promoters were more active and were specific to flowers and fruits, which are organs that are preferentially attacked by important pest insects such as the boll weevil (Anthonomus grandis). The activity of the promoters was also confirmed using transient expression assays in flower buds of $G$. hirsutum. The promoters of GhPME-like1, GhßGal-like1 and GhPL-likel are specific to reproductive tissues and could represent important biotechnological tools for controlling insect pests, in particular the cotton boll weevil, which attacks floral and fruit tissues.

Keywords Cotton · Flower specific genes $\cdot$ Promoter characterization $\cdot$ GUS $\cdot$ CaMV35S $\cdot$ Cotton boll weevil

O. B. Oliveira-Neto $\cdot$ M. F. Grossi-de-Sa Parque Estação Biológica (PqEB), Embrapa Genetic Resources and Biotechnology, Av. W5 Norte (final), Caixa Postal 02372, CEP 70770-900 Brasília, DF, Brazil

O. B. Oliveira-Neto

e-mail: osmundobrilhante@gmail.com

M. F. Grossi-de-Sa

e-mail: fatimasa@cenargen.embrapa.br

O. B. Oliveira-Neto

Department of Biochemistry and Molecular Biology, School of Medicine, FACIPLAC, SIGA AE2, Brasília 72460-000, DF, Brazil e-mail: osmundobrilhante@gmail.com

M. F. Grossi-de-Sa

University Catholic of Brasilia, Brasília, DF, Brazil 


\section{Introduction}

Cotton is a commercial crop that provides $90 \%$ of the raw material for the textile industry and contributes $60 \%$ of the world's oilseed requirements. However, cotton production is hampered by several insect pests that attack during the flowering and fructification of the plant, such as the fall armyworm (Spodoptera frugiperda), the budworm (Heliothis virescens) and the cotton boll weevil (Anthonomus grandis). Together, these insect pests are responsible for more than $50 \%$ of insecticide costs borne by the Brazilian cotton crop farmer. Among the major pests, the cotton boll weevil pest is undoubtedly the most devastating (Greenberg et al. 2003; Martins et al. $2007 b)$. The endophytic habit of the $A$. grandis larvae within the floral buds or cotton fruit destroys fiber quality and hampers chemical control (Haynes and Smith 1992). The most promising, cost effective and sustainable method for controlling cotton boll weevil is the development of genetically resistant cotton lines that suppress the development of the insect larvae (Grossi-de-Sa et al. 2007).

The source of the insecticidal toxins produced by commercial transgenic plants is the soil bacterium Bacillus thuringiensis (Bt). Bt strains show different specific insecticidal activities and contribute a large reservoir of genes encoding insecticidal proteins (Sanahuja et al. 2011). Silencing genes important for insect viability via the use of RNAi is another example of a promising strategy for insect pest control in agriculture (Mao et al. 2007). A recent study producing transgenic maize dsRNA directed against V-type ATPase of corn rootworm showed suppression of mRNA in the insect and reduction in feeding damage (Baum et al. 2007).

However, to increase the sustainability of genetically modified plants (GMP) in agriculture, it is crucial to develop tools that control more precisely heterogeneous expression of entomotoxic proteins or double-stranded RNA. Promoters that show high activity in tissues attacked by insect pests are highly desirable. Many of the promoters already in use in crop plants show conspicuous and high expression levels, such as the maize ubiquitin (Christensen and Quail 1996), rice actin (Zhang et al. 1991), banana streak virus (Schenk et al. 2001) and cauliflower mosaic virus 35S (CaMV35S) promoters (Guilley et al. 1982). Of these promoters, the CaMV35S is the one used most frequently to drive constitutive transgene expression (Odell et al. 1985; Chitkowski et al. 2003). However, CaMV35S promoter activity in floral tissues of cotton plants has been observed to be variable (Kranthi et al. 2005). Moreover, the expression of the Bt toxin Cry1A in ovaries for example is one of the lowest found in different cotton tissues (Kranthi et al. 2005). This pattern of expression is particularly critical to insects that attack these tissues, such as the cotton bollworm and the cotton boll weevil (Kranthi et al. 2005; Olsen et al. 2005; Martins et al. 2007a). Additionally, mRNA levels of the CrylAc (Ingard $\left.{ }^{\circledR}\right)$ gene and the selectable marker gene $N p t I I$, both driven by the CaMV35S promoter, have been shown to decline during cotton plant development (Olsen et al. 2005). Laboratory and glasshouse studies have also suggested that CaMV35S activity is influenced by unknown physiological and possibly also environmental factors (Sunilkumar et al. 2002).

In addition to these negative aspects to the use of the CaMV35S promoter, the identification of new plant promoters is also crucial for the generation of plants with multiple traits (gene stacking) - a typical strategy used in plant biotechnology. If the same promoter is used to drive the expression of more than one transgene, sequencedependent homologous silencing (transcriptional silencing) may occur. This problem is particularly evident when the promoter is also highly active, and it leads to impaired expression of one or more transgenes (Rocha et al. 2005). Thus, for successful gene stacking, promoters with little or no homology must be used in order to circumvent transcriptional gene silencing.

In this study, we isolated and characterized three new promoters that are active predominantly in cotton flowers, and that may provide more consistent levels of protein expression. The genes were initially identified as being highly expressed within an EST library of whole flowers. The expression patterns of these genes were evaluated in different plant organs, floral verticils and also during flower and fruit development. The activities of the corresponding flower gene promoters were then analyzed qualitatively and quantitatively in transgenic Arabidopsis plants using the GUS ( $\beta$-glucuronidase) reporter gene. Their expression in reproductive tissues of cotton was confirmed using transient expression assays. In addition, the activity of the three promoters was compared to the CaMV35S promoter.

\section{Materials and Methods}

\section{Plant Material and Growth Conditions}

Cotton (Gossypium hirsutum variety "BRS Cedro") plants were grown under controlled temperature $\left(27 \pm 2{ }^{\circ} \mathrm{C}\right)$ and natural photoperiod conditions at Embrapa Genetic Resources and Biotechnology (Brasília, DF, Brazil). Different vegetative and reproductive tissues from 3month-old plants were used for qPCR experiments and for promoter isolation. For transient cotton transformation, 6-mm floral buds were used.

Arabidopsis thaliana ecotype Landsberg erecta (Ler) was transformed using the floral dip method to analyze promoter activity by fusing to the $\beta$-glucuronidase (GUS) reporter gene (Desfeux et al. 2000; Clough and Bent 1998). 
In silico Analyses and Identification of G. hirsutum Flower-Specific Genes

To identify flower-specific genes, two separate databases were used: the PAVE library (http://www.agcol.arizona.edu/cgibin/pave/Cotton/index.cgi, Udall et al. 2006) and the Cotton Genome Database (US Department of Agriculture, Agricultural Research Service CottonDB, http://cottondb. org/cdbhome.html). Initially, 19 genes were selected from the PAVE library of whole flowers of Gossypium raimondii at the post-anthesis stage ( -3 to +3 days) that showed high expression (seven or more ESTs). The sequences of these 19 genes were analyzed using BLASTN in the Arabidopsis database to find putative homologues (see supplementary Table S1). The homologues were scrutinized using the Genevestigator platform (https://www.genevestigator.com/gv/) to visualize reproductive-tissue specific expression. Seven genes showed high expression in flower tissues. The sequences of these genes were compared with sequences of $G$. hirsutum genes in the Cotton Genome Database using the tBLASTN program (Altschul et al. 1997). Multiple alignments for each gene family using amino acid sequences obtained from G. hirsutum (see Supplementary Table S1), G. raimondii and Arabidopsis were conducted using the CLUSTALW2 program using default parameters that were then revised manually (Larkin et al. 2007). Phylogenetic trees were constructed after using model test to pick the most appropriate evolutionary model for our analysis in the Mega 5.2 program (Saitou and Nei 1987; Tamura et al. 2011). The best-fitting amino acid substitution model for all gene families was WAG (Whelan and Goldman 2001) with estimated $\gamma$-distribution parameter (G). For $\beta$-galactosidase reconstruction, an estimated proportion of the invariable sites (I) was also implemented. The maximum-likelihood analyses were performed with the program PhyML version 3.0 (Guindon et al. 2010; http://www. atgc-montpellier.fr/phyml/) and assessment of node confidence was performed using 1,000 bootstrap replicates (see supplementary Fig. S1). The amino acid sequences deduced as GhPME-likel (240 amino acid), GhßGal-likel (879 amino acid), and GhPL-likel (275 amino acid) genes were evaluated in the PFAM database (http://pfam.sanger.ac.uk/search) to determine protein domain architectures that could provide insight into their function (Finn et al. 2006) (data not shown). The expression pattern of these genes was evaluated in different cotton tissues using qPCR.

Analyses of Expression Patterns of Endogenous Genes in Cotton

The organs used from the cotton plants comprised flower buds, fruits, leaves, stems, branches and roots. We also included seven stages of flower development (flower buds of the following diameters: $2,4,6,7,8,10$ and $12 \mathrm{~mm}$ ) and four stages of fruit development (boll of the following diameters: $10-15,16-20,21-30$ and $>30 \mathrm{~mm}$; the stages of flower and fruit and the respective major events of development are summarized in Artico et al. 2010). In addition, floral organs (sepal, petal, stamen, carpel and pedicel) from 6-mm flower buds were dissected and harvested (because the flower stage is preferred for feeding and oviposition of the cotton boll weevil). Material from at least five different cotton plants was harvested and pooled. Total RNA extractions were performed using Invisorb Spin Plant RNA Mini kit (Invitek), according to the manufacturer's protocol. For amplification of the corresponding genes, cDNAs were synthesized from $1 \mu \mathrm{g}$ total RNA using Oligo (dT24V) primers and Superscript III (Invitrogen, Carlsbad, CA), according to the manufacturer's instructions. Primers were designed using Primer 3 software (Rozen and Skaletsky 2002; see supplementary Table S2). Polymerase chain reactions were performed in the 7500 Fast Real-Time PCR detection system (Applied Biosystems, Foster City, CA) using SYBR ${ }^{\circledR}$ Green to monitor dsDNA synthesis. PCR efficiencies and optimal quantification cycle threshold or $\mathrm{Cq}$ values were estimated using the online Real time PCR Miner (Zhao and Fernald 2005). Two independent biological samples of each experimental condition were evaluated using triplet technical replicates. The reference genes used to normalize the qPCR data have been discussed previously (Artico et al. 2010; see supplementary Table S2).

\section{Isolation of Promoter Sequences of Flower-Specific Cotton} Genes

Genomic DNA was extracted from cotton leaves using NucleoSpin Plant II (Macherey-Nagel, http://www.mnnet.com). Based on the EST sequences of the genes GhPME-like1, GhßGal-like1 and GhPL-like1, reverse primer and reverse-nested primers were designed to isolate promoter sequences using the Genome Walker kit (Clontech, Palo Alto, CA), according to the manufacturer's instructions (see supplementary Table S3). Isolated fragments were cloned into the pGEM-T_Easy vector (Promega, Madison, WI), sequenced and assembled into promoter sequences of approximately 350, 780, 1639 bp in length for GhPME-likel and 383 bp and 514 bp in length for GhßGal-like1 and GhPL-like1, respectively (see supplementary Fig. S2a,b,c). The transcription initiation site (TIS) was determined experimentally using the GeneRacer Kit (Invitrogen; see supplementary Fig. S2a-c and supplementary Table S3).

Sequence Analysis of Flower-Specific Promoters

The isolated promoter sequences of GhPME-like1, Gh $\beta G a l$ likel and GhPL-likel were scrutinized using the PlantCARE (Lescot et al. 2002), PLACE (Higo et al. 1999; Prestridge 1991) 
and Plant-PAN (Chang et al. 2008) software packages to determine plant cis-acting regulatory DNA elements.

\section{Construction of Expression Vectors Used for Arabidopsis} and Cotton Transformation

The promoter regions were amplified and isolated by PCR using promoter-specific primers and Phusion High-Fidelety DNA Polymerase (Finnzymes, Espoo, Finland) from $100 \mathrm{ng}$ gDNA (see supplementary Table S3). The purified PCR products were cloned into the $\mathrm{pENTR}^{\mathrm{TM}}$ Directional TOPO cloning entry vector (Invitrogen), and subsequently recombined into the pKGWFS7 destination vector bearing the GUS reporter gene, thus generating the recombinant destination clones p300_GhPME-like1::GUS; p760_GhPME-like1::GUS; p1618_GhPME-like1::GUS; pGh $\beta$ Gal-like1::GUS; and pGhPl-like1::GUS. All recombinant plasmids were transformed into Agrobacterium tumefaciens GV3101. These constructs were used to transform Arabidopsis (Ler) using the floral dip method (Clough and Bent 1998). Transgenic plants were selected on agar plates containing $50 \mathrm{mg} / \mathrm{L}$ kanamycinand the integration of promoter-GUS fusions to transgenic plants was confirmed by PCR using primers derived from promoter and GUS sequences (data not shown). More than ten independent lines were produced for each construct, and at least three different transgenic lines of T3 homozygous plants expressing each construct were employed for GUS analyses and quantification.

The promoter regions were tested in transient expression experiments by particle bombardment in 5- to $6-\mathrm{mm} G$. hirsutum flower buds. The preparation of tungsten microparticles was performed as described by Rech et al. (2008). Bombardment used the PDS-1000/He system (Bio-Rad, Hercules, CA) under gas helium pressure, set with 1200 psi $\mathrm{He}$ and $25 \mathrm{polHg}$ vacuum. After bombardment, the biological material was assayed using GUS histochemical staining.

\section{Histochemical and Fluorimetric GUS Assays}

For the histochemical assays, plant tissues were stained for GUS activity based on the method of Jefferson (1987). For each construct, tissues were collected from at least five different plants. Samples were observed under a Leica Wild Heerbrugg M3Z Stereozoom Microscope (Leica, Wetzlar, Germany).

For quantitative fluorimetric GUS assays, inflorescences, flower buds, open flowers, siliques, stems, leaves and roots were used (see supplementary Table S4). Total protein was quantified according to Bradford (1976) using bovine serum albumin (BSA) as a standard. GUS specific activity was calculated as picomoles of 4-methylumbelliferone (4-MU) produced per minute per microgram of soluble protein. Data are presented as the mean GUS activity from at least three independent determinations.

Real-Time PCR Analysis of Arabidopsis Transgenic Plants

Total RNA was extracted from inflorescences, flower buds, open flower, siliques, stem, leaves and roots of transgenic Arabidopsis plants expressing p300_GhPME-like1::GUS; p760_GhPME-like1::GUS; p1618_GhPME-like1::GUS; and $\bar{p}$ Gh $\beta$ Gal-like $1::$ GUS or pGhPl-like $1::$ GUS and CaMV35S::GUS constructions as described by OnãteSánchez and Vicente-Carbajosa (2008) (see supplementary Table S4). For each construct, three independent transgenic lines were chosen for qPCR analysis using three technical replicates. Expression levels of promoter-uidA were normalized to At1g13320 and At1g58050 Arabidopsis reference genes (Czechowski et al. 2005; see supplementary Table S2).

\section{Microscopic Examination}

To identify the cellular expression patterns, histological sections were obtained from Arabidopsis flowers expressing the constructions described above. For sectioning, flower samples processed for GUS histochemical analysis were fixed using $3 \%(\mathrm{v} / \mathrm{v})$ glutaraldehyde solution and then dehydrated in a graded ethanol series and embedded in acrylic resin (HISTORESIN Embedding Kit, Leica Microsystems Germany). Resin-embedded samples were sliced into 2- to $5-\mu \mathrm{m}$ sections using an ultra-microtome (Micron HM 325 Microtime). Tissue sections were observed under a light microscope (Leica DMR).

\section{Results}

Identification of Genes with Specific Expression in Cotton Flowers

With the aim of identifying and isolating new tissue-specific promoters in cotton flowers, we first identified genes expressed predominantly in flowers. The search was performed using two databases: the PAVE and the Cotton Genome Database. The PAVE database is particularly informative and contains approximately 185,000 Gossypium EST sequences distributed among $30 \mathrm{cDNA}$ libraries from a variety of tissues and organs and also under a range of conditions. The libraries are derived from allopolyploid cotton (G. hirsutum; A and D genomes) and its two diploid progenitors Gossypium arboreum (A genome) and Gossypium raimondii (D genome). Assembly of ESTs of the PAVE databank resulted in 22,030 contigs and 29,077 singletons (51,107 unigenes; Udall et al. 2006). We focused our analysis on the G. raimondii flower library. This library includes buds 
from -3 dpa to bolls of +3 dpa (days post anthesis), and it contains 35,061 ESTs and 13,344 contigs, which are termed GR-Eb in the PAVE databank. We initially selected genes that were highly expressed with seven or more ESTs in this library. A total of 640 contigs ( $4.7 \%$ ) were identified as being highly expressed in floral tissues. Among this group of contigs, 19 $(0.14 \%)$ present ESTs in the flower library only. The sequences of the 19 genes from the flower library of $G$. raimondii were used to identify putative homologs in the Arabidopsis genome (listed in supplementary Table S1). The expression of putative Arabidopsis homologs was evaluated using the Genevestigator platform (Zimmermann et al. 2004; data not shown). G. raimondii genes were selected that had putative homologs in Arabidopsis of high and specific expression in floral tissue. The seven genes with high and specific expression in floral tissue selected from $G$. raimondii were used to search for G. hirsutum homologs in the Cotton Genome Database (listed in supplementary Table S1). The $G$. hirsutum genes were evaluated by qPCR analysis, and three genes showed high expression in cotton flowers (Fig. 1a). The amino acid sequences deduced to these genes show high sequence similarity to genes encoding enzymes involved in the biosynthesis and degradation of the cell wall. The genes encode a pectin methyl esterase (PME) (Family: PMEI, Plant invertase/ pectin methylesterase, pfam04043), $\beta$ galactosidase (BGAL) (Family: Glycosyl hydrolase 35, pfam01301) and pectate lyase (PL) (Family: Pectate lyase, pfam04431). For clarity, we have termed these genes GhPMElike1 (gi|193217860), GhßGal-like1 (gi|45758291) and GhPL-like1 (gi|68131791) (see supplementary Table S1). Phylogenetic analysis showed that the G. hirsutum GhPMElikel gene is grouped with the PME clade that is expressed predominantly in flower buds in Arabidopsis (Louvet et al. 2006; see supplementary Fig. S1a). Phylogenetic analysis indicated that the G. hirsutum Gh $\beta$ Gal-likel gene was grouped together with the Arabidopsis $\beta \mathrm{GAL}$ flowerspecific genes $\beta$ GAL 14, $\beta$ GAL 11 and $\beta$ GAL 13 (see supplementary Fig. S1b; Ahn et al. 2007). Finally, phylogenetic analysis of the GhPL-like1 gene with the PL family of Arabidopsis also suggested similarities in the proteins and in tissue expression activity. The Arabidopsis genes PLL 8 and 9, which belong to the same clade as GhPL-like1, show greater flower-specific expression (Palusa et al. 2007; see supplementary Fig. S1c).

The expression of GhPME-like1, GhßGal-like1 and GhPL-likel was explored in detail in different cotton organs during flower and fruit development and also in different floral organs. The transcript levels of GhPME-like1, GhßGal-likel and GhPL-likel were much greater in flowers than in other plant organs. Moreover, their expression was almost undetectable in leaf, stem or branch tissues (Fig. 1a). GhßGal-likel is also expressed in cotton fruit, which is a feeding site of the boll weevil. Expression analysis during fruit development showed that GhßGal-likel is expressed at a higher level at earlier stages during fruit development (10-15 and 16-20 $\mathrm{mm}$ ) and decreases dramatically during the later stages of cotton fruit development (21-30 and $>30 \mathrm{~mm}$; Fig. 1b). We next evaluated the expression of GhPME-like1, GhßGal-like1 and GhPL-likel during flower development. The results showed that transcript levels of the three genes were high in flower buds of 4-12 mm (Fig. 1c). In addition, to obtain a detailed portrait of the gene expression profile, we verified the expression level of GhPME-like1, GhßGal-like1 and GhPL-likel genes in different floral verticils of 6-mm floral buds. GhPME-like1, GhßGal-like1 and GhPL-like1 showed an extremely high relative expression in stamens compared with other floral organs but they were also expressed in petals, sepals and carpels (Fig. 1d).

Isolation of the Promoter Sequences of GhPME-like1, GhßGal-like1 and GhPL-like1

Because these genes show expression predominantly in floral tissues and/or fruit, we decided to isolate their regulatory regions and evaluate them as potential candidates for driving expression in reproductive tissue. The region immediately upstream of the translation initiation codon (ATG) of GhPME-like1, GhßGal-likel and GhPL-likel was isolated using the Universal Genome Walker kit (primers are listed in supplementary Table S3). The promoter sequences isolated, cloned and sequenced of GhPME-likel was 350 bp long, 383 bp for GhßGal-like1 and 514 bp for GhPL-like1. We decided to evaluate the activity of these fragments in vivo prior to further isolations. This decision was based on the presence of several putative flower-specific regulatory motifs in these short fragments (see below). In addition, the use of short proximal promoters facilitates their manipulation and employment in plant biotechnology (Potenza et al. 2004; Odell et al. 1985; Fang et al. 1989). The transcription initiation sites (TIS) of the three genes studied were determined by cloning the full transcript using 5'-RACE PCR (see supplementary Fig. S2; primers are listed in supplementary Table S3). The promoters regions of GhPME-like1, GhßGal-likel and GhPL-likel were analyzed for the presence of putative regulatory motifs using the PLACE, PlantCARE and Plant-PAN databases. Various putative cis-acting regulatory elements were predicted as generic plants cis-elements, such as the TATA-box and CAAT-box (see supplementary Fig. S2). In addition, all promoters isolated present a large number of cis-elements related to pollen- and anther-specific expression. For example, the cis-element POLLEN1LELAT52 (sequence AGAAA) is repeated six times in the GhPME-likel gene promoter, four times in the GhßGal-likel gene promoter and three times in the GhPL-likel gene promoter (see supplementary Fig. S2a-c). POLLEN1LELAT52 activity correlates with pollen development in tomato (Bate and Twell 1998). The 

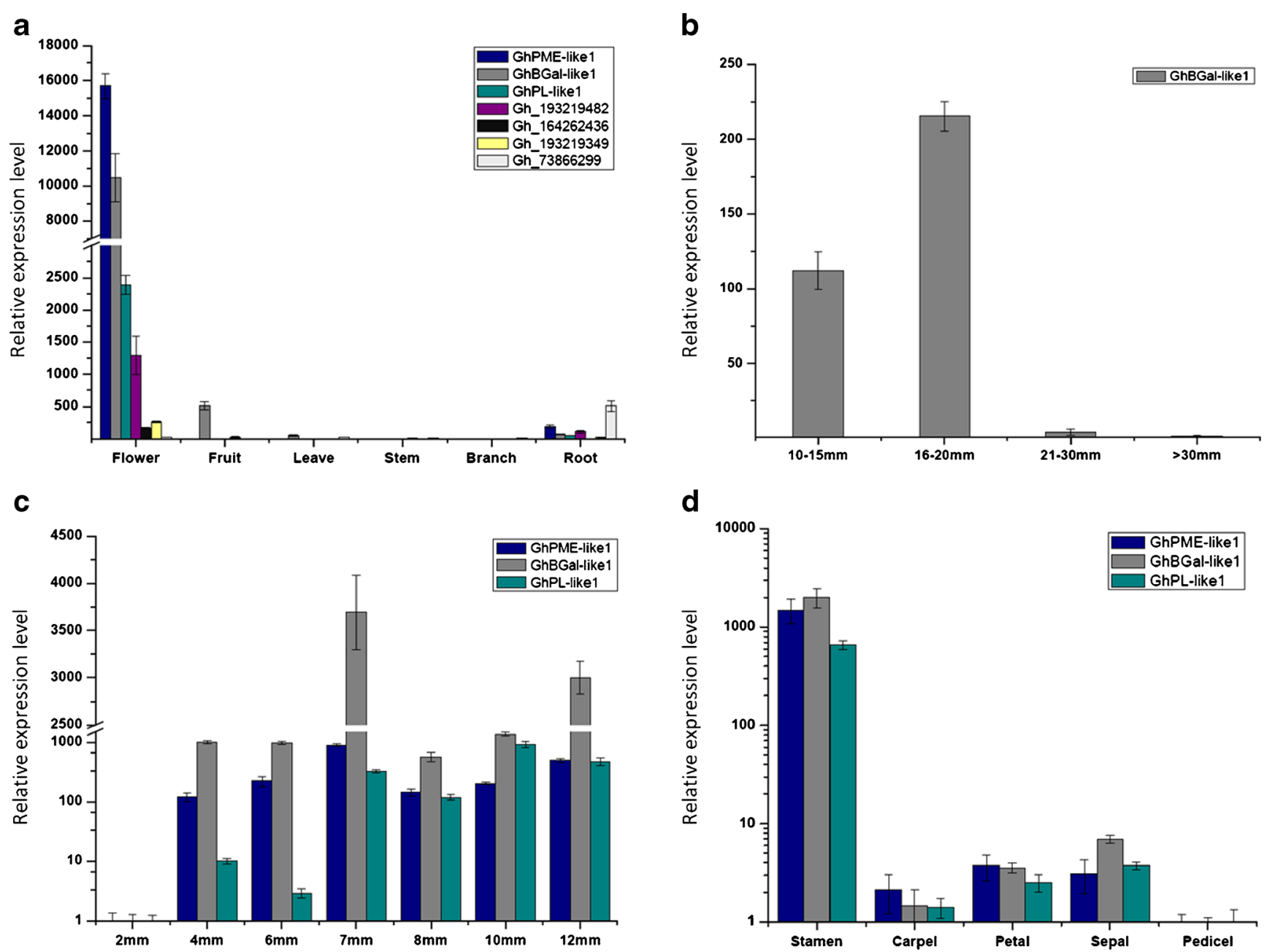

Fig. 1 a Relative mRNA level of seven putative flower-specific genes of Gossypium hirsutum in different plant organs. b-d Relative mRNA level of the three GhPME-like1, Gh $\beta$ Gal-like1 and GhPL-like1 genes show high expression in cotton flowers during fruit (b) and flower (c) development and in different floral organs (d). $\mathrm{Cq}$ and amplification efficiency values were processed using qBase software. Normalization

Gh $\beta$ Gal-like1 promoter also contains a fruit-specific element, TGTCACAMCUCUMISIN (sequence TGTCACA), identified in the promoter of the cucumisin gene of melon (Yamagata et al. 2002) (see supplementary Fig. S2). The full list of cis-acting elements found in the cotton promoters may be viewed in supplementary Tables S5, S6 and S7.

Activity of Promoter:GUS Constructions in Various Tissues of Transgenic Arabidopsis Plants

To investigate promoter activity, regulatory sequences of GhPME-like1 (300 bp), GhßGal-likel (356 bp) and GhPLlikel (435 bp) were fused to the uidA gene in binary vectors and used to transform Arabidopsis. All constructs, named pGhPME-like1::GUS; pGh $\beta$ Gal-like1::GUS; and pGhPllike1::GUS, were transformed into Arabidopsis using Agrobacterium-mediated transformation. For each construct,

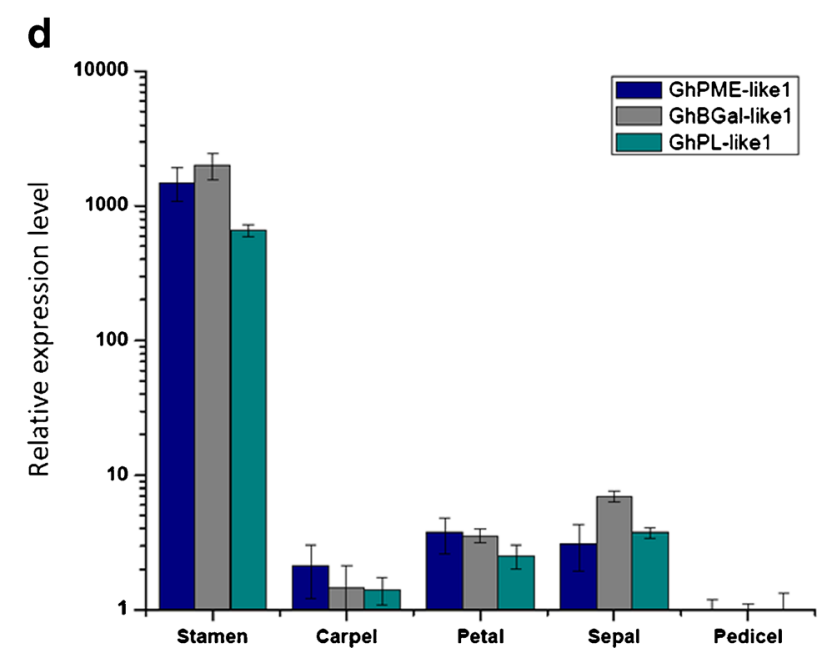

was performed using the best combination of reference genes recommended by Artico et al. (2010). A combination of GhUBQ14 and $G h P P 2 A 1$ genes was used as an internal control for plant organs (a), whereas $G h M Z A$ and $G h P T B$ was used for fruit development (b), GhACT4 and GhUBQ14 for flower buds (c), and GhACT4 and GhFBX6 for floral organs (d)

more than 12 homozygous plants with only one T-DNA insertion were evaluated. No differences were observed in the promoter activity of each construct within the transgenic lines evaluated. For GhPME-like1, the expression of GUS in flowers was robust and specific to the stamen of young flower buds (stage 11) when the stigmatic papillae are formed (Fig. 2a-g). Staining in the stamens remained intense during later stages of development of the flower bud (Fig. $2 \mathrm{f}-\mathrm{h}$ ). As shown in Fig. $2 \mathrm{~g}$ and in detail in $2 \mathrm{~h}, \mathrm{j}$ and $\mathrm{l}$, GUS expression was intense in pollen grains and the inner layer of the anther wall in endothecium cells. Staining was also observed in the style and in the apical region of the stigma during later stages of development and until fruit development (Fig. 2g, h, j, 1). The GhPME-likel promoter also shows residual activity in Arabidopsis seedlings and in the main root (see supplementary Fig. S3a-c). Histochemical staining for GUS from the pGh $\beta$ Gal-like1::GUS construct was robust in buds and open 

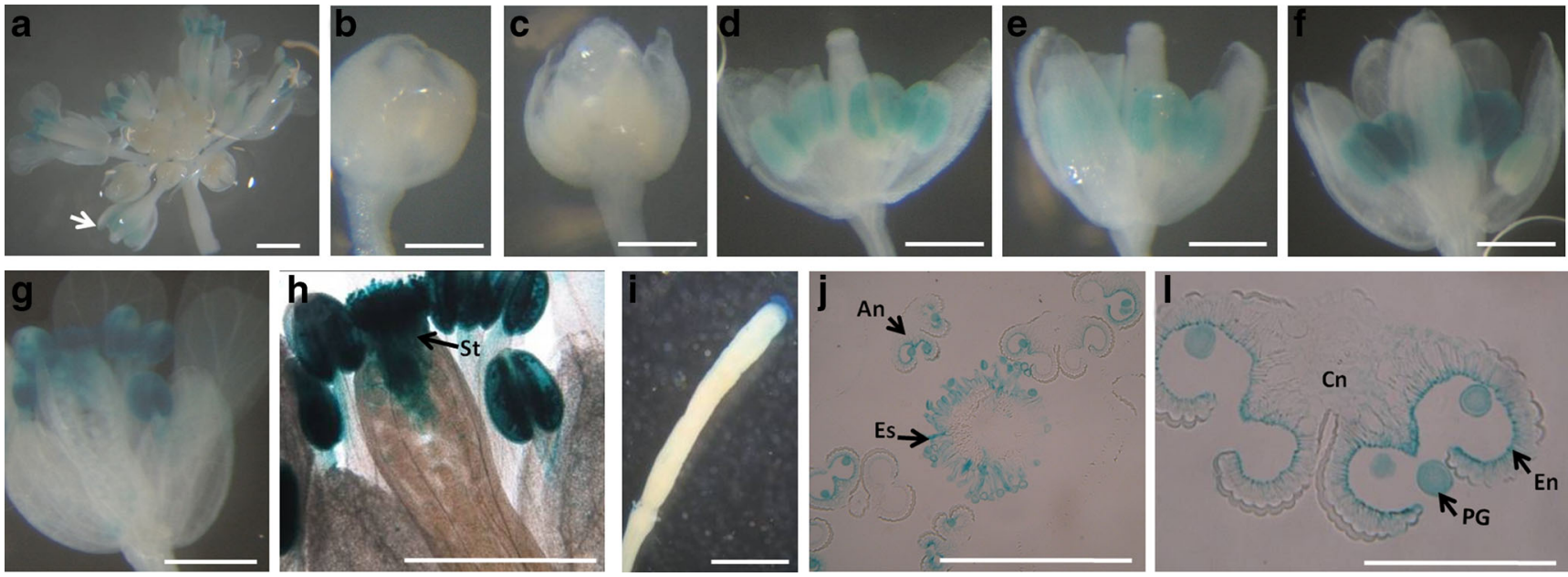

Fig. 2 a-l Histochemical analysis of $\beta$-glucuronidase (GUS) expression in flowers buds of transgenic Arabidopsis plants expressing the pGhPMElike1::GUS promoter. GUS expression was detected in stamens $(\mathbf{d}-\mathbf{h})$, in particular in anthers (An), pollen grains (PG) and endothecium cells (En) $(\mathbf{j}-\mathbf{l})$. Robust GUS staining was observed in the apical portion of the stigma

(Es), in stigmatic cells, the stylus $(\mathbf{g}-\mathbf{h}, \mathbf{j})$ and in the apical portion of the siliques (i). $\mathbf{j}-\mathbf{l}$ Cross-sections of the flower bud and anther; $C n$ endothecium tissues. a Arrow Stage 11 of flower development in Arabidopsis. b Stage 6 of flower development; c Stage 8; d Stage 11; e Stage 13; f Stage 13; (g, h, j, l) Stage 14, St stylus; (i) Stage 17a. Bar $250 \mu \mathrm{m}$

flower during the later stages of flower development (stage 12; Fig. 3a-f). Strong GUS staining was observed primarily in anthers (Fig. 3d-h) and more specifically in pollen grains, connective tissue and endothecium cells (Fig. 3g, h, j). Staining was also observed in the upper portion of the carpels, in stigmatic cells and the style of the flower (Fig. 3f-g). Promoter activity was also observed in the apical region of the siliques (Fig. 3i). pGh $\beta$ Gal-like1::GUS seedlings showed slight GUS staining in the cotyledon leaf margin (see supplementary Fig. S3g, h). pGhPL-likel promoter activity was observed in Arabidopsis flowers (Fig. 4a-g), primarily in anthers, connective tissues, endothecium cells and pollen grains (Fig. 4c-h, 1). Similar to the promoter construct pGh $\beta$ Gal-like1::GUS, pGhPL-like1 directs expression of

GUS to stigmatic cells and the style (Fig. 4f, g) and siliques (Fig. 4i, j). GUS staining was also observed in the leaf primordium in Arabidopsis seedlings (see supplementary Fig. S3i, j). As expected from qPCR expression data of these genes in cotton tissues, no significant promoter activity was detected in vegetative organs of 5-week-old Arabidopsis transgenic plants carrying the constructs pGhPMElike1::GUS, pGh $\beta$ Gal-like1::GUS; or pGhPl-like1::GUS (see supplementary Fig. S3d, e, f).

\section{Quantitative Analysis of Promoter Activity}

To compare activity levels of the cotton promoters in discrete Arabidopsis organs, the GUS activity of T3 promoter:gus
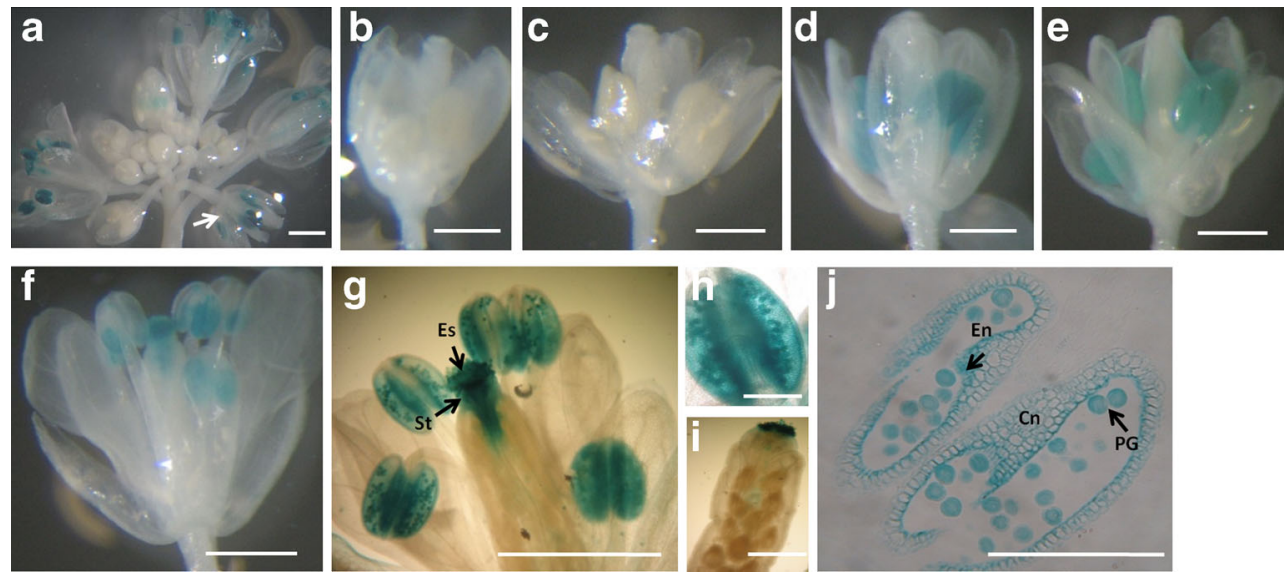

Fig. $3 \mathbf{a}-\mathbf{j}$ Histochemical analysis of GUS expression in flowers buds of transgenic Arabidopsis plants expressing the pGh $\beta$ Gal-like1::GUS promoter. Robust GUS staining was observed in the anthers $(\mathbf{a}, \mathbf{d}-\mathbf{h})$ and in particular in pollen grains (PG) $(\mathbf{g}, \mathbf{h}, \mathbf{j})$ and endothecium cells $(\mathrm{En})(\mathbf{j})$. Strong GUS staining was observed in the apical portion of the stigma

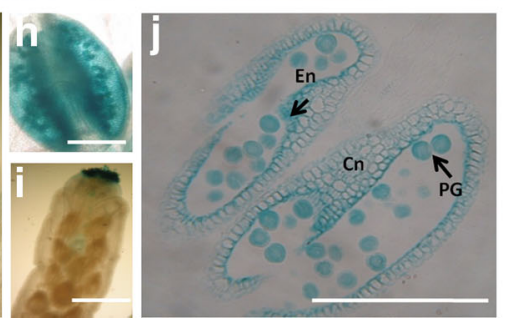

(Es), in stigmatic cells and the stylus (St) (f-g) and apical portion of the siliques (i). (j) Cross-section of the anther; $C n$ connective tissue. (a) Arrow Stage 12 of flower development in Arabidopsis. b, c Stage 8 of flower development; d Stage 12; e Stage 13; f, g, h, j Stage 14; i Stage 17a. Bar $250 \mu \mathrm{m}$ 

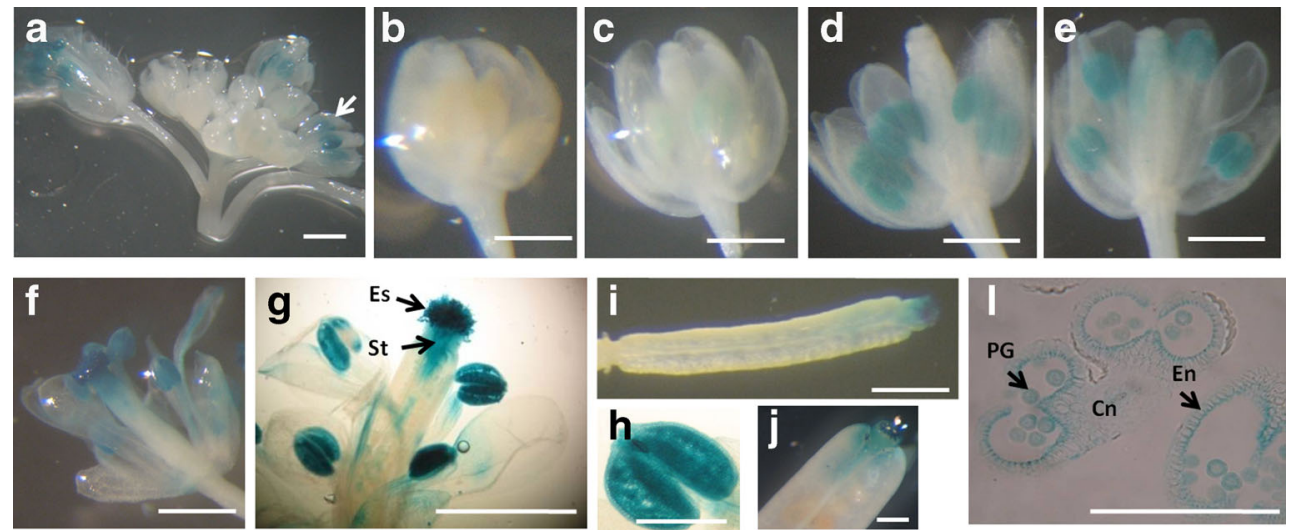

Fig. 4 a-I Histochemical analysis of GUS expression in flowers buds of transgenic Arabidopsis plants expressing the pGhPl-like1::GUS promoter. GUS is expressed in stamens of young flower buds $(\mathbf{a}, \mathbf{c})$ through to mature flower buds (f, $\mathbf{g}$ ). GUS staining is restricted to anthers and primarily to endothecium cells (En) and pollen grains (PG) and connective tissues $(\mathrm{Cn})$

transgenic lines was measured using quantitative fluorimetric analysis of the MUG substrate (Fig. 5). Transgenic plants carrying the promoter constructs were evaluated and compared with those carrying constitutive CaMV35S::GUS promoters and wild-type plants. GUS enzyme activity driven by $p G h P M E$-like1, $p$ Gh $\beta G a l-l i k e 1$ and $p G h P l-l i k e 1$ cotton promoters was determined from reproductive and vegetative organs of the transgenic lines. Quantitative GUS assays of the cotton promoters showed a high level of expression in reproductive tissues compared with vegetative tissues (Fig. 5a). In contrast, as expected, CaMV35S promoter activity was greater in roots, stems and leaves compared with the three cotton promoters (Fig. 5a). GUS activities in inflorescences, when compared with leaves of plants carrying the cotton promoters,

a

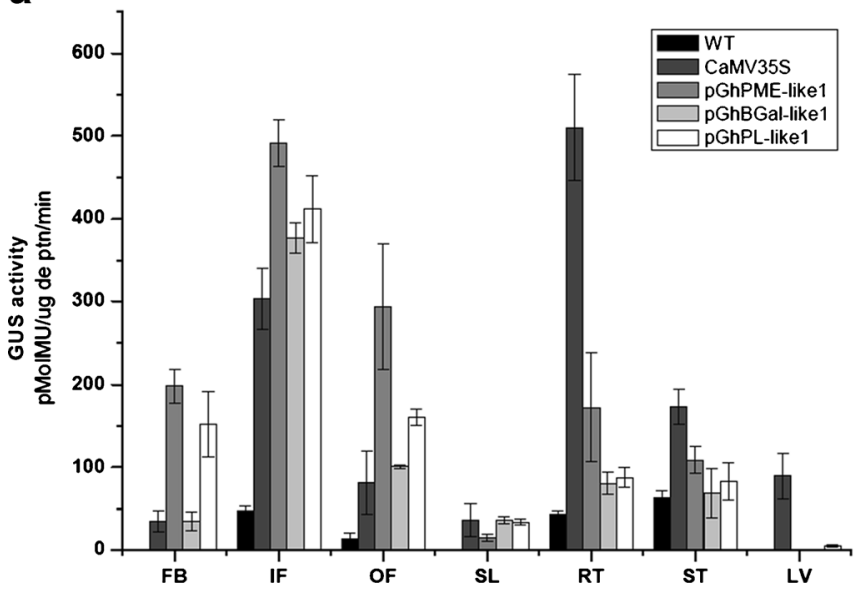

Fig. 5 Comparison of GUS expression via quantitative analysis of the MUG substrate. GUS activity was identified in flower buds $(F B)$, inflorescences $(I F)$, open flowers $(O F)$, siliques $(S L)$, roots $(R T)$, stems $(S T)$ and leaves $(L V)$. The data represent GUS activity \pm standard error of the mean (SEM) of three replicates from three independent transgenic lines. a Comparison of GUS expression levels driven by the pGhPME-like1, $(\mathbf{h}, \mathbf{l})$. GUS blue is expressed in stigmatic cells and the stylus (St) $(\mathbf{f}-\mathbf{g})$ and in the apical region of the siliques $(\mathbf{i}-\mathbf{j})$. I Cross-section of an anther. Es Stigma. a Arrow Stage 11 of flower development in Arabidopsis. b Stage 6 of flower development; c Stage 8; d Stage 11; e Stage 13; f, g, h, and I Stage 14, j Stage 17a. Bar $250 \mu \mathrm{m}$

were at least 12.5 -fold higher (Fig. 5a). When expression was compared with the $35 \mathrm{~S}$ promoter, the $p G h P M E$-like1 promoter showed the highest GUS activity and was approximately 6fold higher in flower buds.

This analysis showed that the promoter activity of the 300bp fragment of the GhPME-like1 (pGhPME-like1::GUS) promoter in flower buds, inflorescences and open flowers was greater than that of the GhßGal-likel and GhPl-like1 promoters (Fig. 5a). Because longer fragments may display even stronger or more specific flower activity, we decided to isolate and evaluate the largest promoter of this gene. From the longer fragment isolated (1,639 bp), we generated two $5^{\prime}$ deletions: p1618_GhPME-like1 and the p760_GhPME-like1. In addition to eight repeats of the cis-element POLLEN1LELAT52,

b

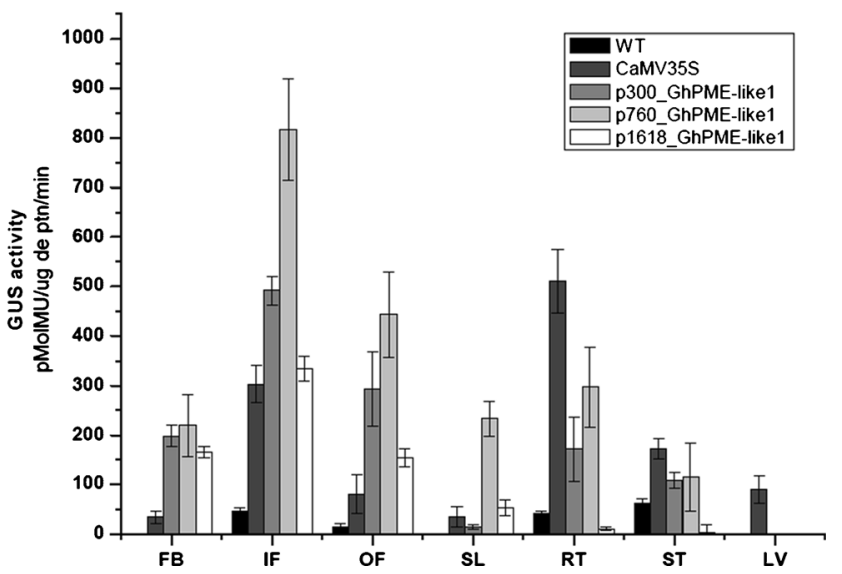

$p G h \beta$ Gal-like1, $p$ GhPl-like1 and CaMV35S promoters in different tissues of transgenic Arabidopsis plants and wild-type plants via quantitative analysis of the MUG substrate. b Enzyme activity of GUS measured in various $5^{\prime}$-deleted cotton GhPME-likel promoters compared with transformed CaMV35S::GUS lines and wild-type plants 
these two fragments carry the MYB.ph3 element (sequence AAACAAATA), which is a DNA binding element of a petal epidermis-specific MYB transcription factor, and the AP1CArGbox element (sequence CCAAA), which is present in the APETALA3 gene promoter. The full list of cis-acting elements found in this promoter is shown in supplementary Table S5. These fragments were fused to the GUS reporter gene and used to transform Arabidopsis. T3 homozygous seeds from 15-20 independent lines were generated for each construct, and the transgenic plants were analyzed for GUS expression using histochemical and quantitative assays as described in the Materials and Methods. The expression of GUS directed by the p760_GhPME-like1::GUS promoter was robust in flowers and particularly in anthers (pollen grains, endothecium cells) and filaments of young flower buds at stage 11 of flower development (Fig. 6a-d, e, o). The p760_GhPME-like1::GUS construct also directed expression of GUS to the vascular bundles of petals (Fig. 6b, c, f), stigmatic cells and the style in the apical portion of the carpel (Fig. 6b-d) and to the apical and basal portion (internodes) of the siliques (Fig. 6g). The 1,618-bp fragment of GhPME-like1 promoter was capable of directing expression of GUS to petals, anthers (pollen grains, endothecium cells) and also the apical portion of siliques (Fig. $6 \mathrm{j}-\mathrm{n}$ ).

Results from GUS enzyme activity assays of three independent Arabidopsis T3 lines expressing each of the promoter constructs of GhPME-likel are shown in Fig. 5b and compared with the constitutive 35S promoter. Quantitative GUS assays of both GhPME-likel gene promoters showed a high level of expression in flower tissues, such as inflorescences, mature flowers, flower buds and also siliques. The highest
GUS activity was observed in the p760_GhPME-like1::GUS lines, which showed approximately 3 - to 6 -fold higher activity in reproductive organs compared the CaMV35S promoter, indicating that it may be a strong promoter specific to cotton flower tissues. GUS activity directed by the largest p1618_GhPME-like1 promoter was lower when compared with the other GhPME-likel promoter fragments but remained higher than that directed by the CaMV35S promoter in flower buds, inflorescences, mature flowers and siliques (Fig. 5b). The activity of the shorter promoter fragment (p300_GhPME-like1) was dramatically higher compared with the CaMV35S in reproductive tissues. Although GUS activity assays have been used successfully for years to characterize promoter activity, we decided to evaluate the activity of the cotton promoters using $\mathrm{qPCR}$ analyses due to its greater sensitivity (Yi et al. 2010; Liang et al. 2011; Koia et al. 2013).

Analysis of uidA Transcripts in Transgenic Arabidopsis Plants by qPCR

To compare the activity levels of cotton promoters in diverse Arabidopsis organs, uidA mRNA levels in T3 promoter:gus transgenic lines were measured using qPCR. For this purpose, total RNA was extracted from flower buds, inflorescences, open flowers, siliques, leaves, stems and roots of transgenic Arabidopsis plants. The levels of promoter-driven uidA transcripts were calculated for all lines with cotton promoter fragments fused to $u i d A$ and also from the CaMV35S::GUS transgenic line. In general, uidA mRNA levels driven by cotton promoters were found to be higher, although variable, in all flowers stages and siliques (Fig. 7a). Thus, all cotton
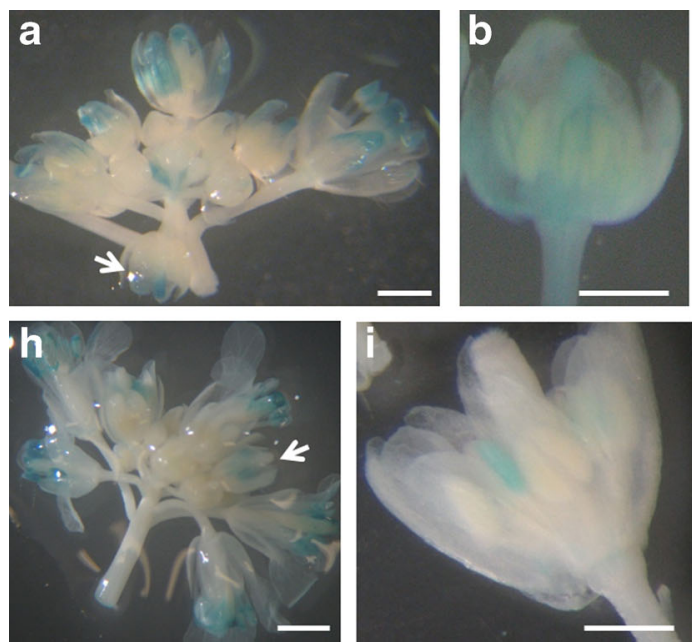

Fig. 6 a-o Histochemical analysis of GUS expression in flowers buds of transgenic Arabidopsis plants expressing the p760_GhPMElike1::GUS $(\mathbf{a}-\mathbf{g}, \mathbf{n})$ and p1618_GhPME-like1::GUS (h-m, o) promoters. For the p760 PME-like1 promoter, GUS expression was detected in stamens and, particularly, in anthers and filaments $(\mathbf{d}, \mathbf{e})$ and in apical portions of the stigma $(\mathbf{b}-\mathbf{d})$, in petals $(\mathbf{b}-\mathbf{d}, \mathbf{f})$ and apical and basal portions (internodes) of the siliques (g). Robust GUS
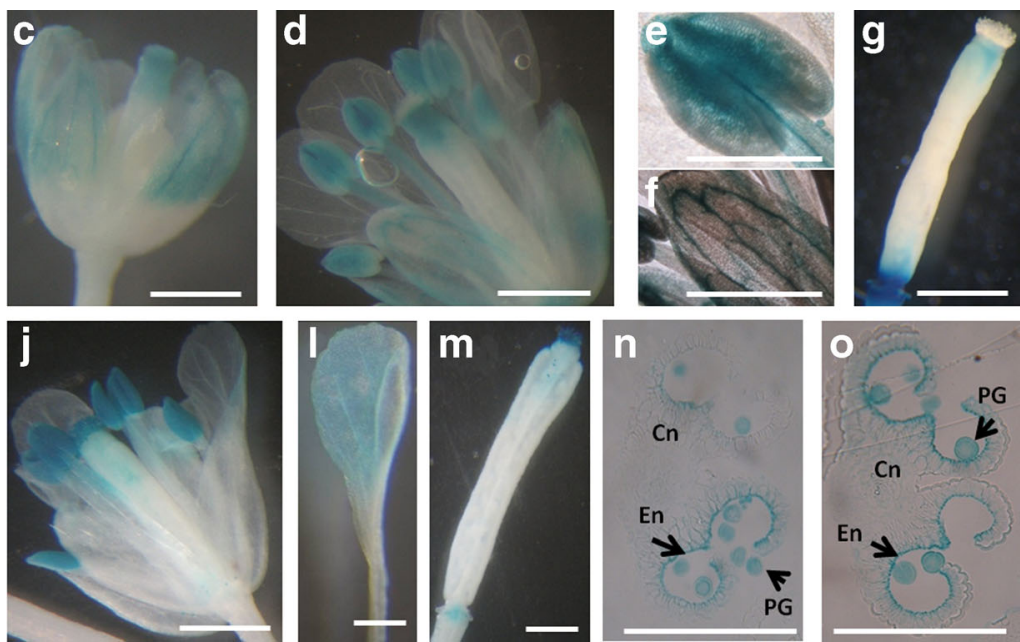

staining was observed directed by the p1618_PME-like1 construct in the apical portion of the stigma $(\mathbf{j})$, in anthers $(\mathbf{i}-\mathbf{j}, \mathbf{n})$, in petals $(\mathbf{I})$ and siliques (m). n, o Cross-sections of anthers from plants expressing p760_GhPME-like1 and p1618_GhPME-like1 promoters, respectively. Arrow Stage 11 of flower development in Arabidopsis $(\mathbf{a}, \mathbf{h}) . \mathbf{b}$ Stage 8 of flower development (c) Stage $9 ; \mathbf{d}, \mathbf{e}, \mathbf{f}, \mathbf{n}$ and $\mathbf{j}, \mathbf{l}, \mathbf{o}$ Stage 14; i Stage 11 and (g, m) Stage 17a. Bar $250 \mu \mathrm{m}$ 


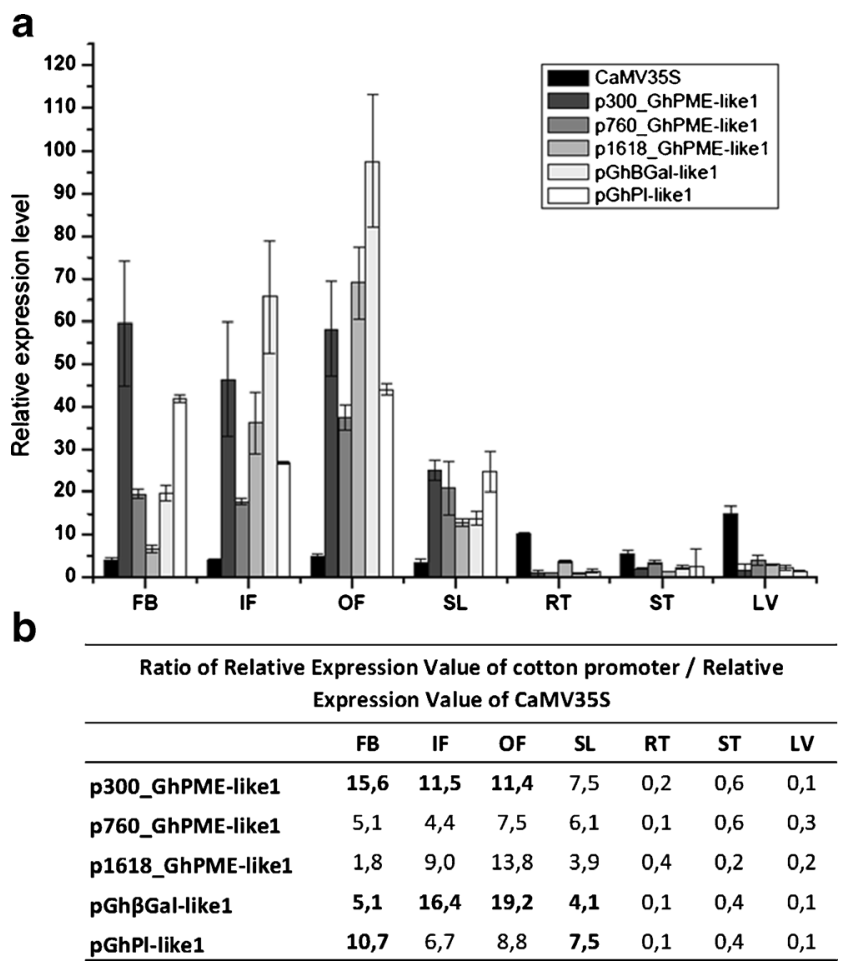

Fig. 7 Relative expression of the cotton promoter/relative expression of CaMV35S. a Relative expression of uidA transcripts, as measured by qPCR, of each cotton promoter:GUS transgenic plant compared with CaMV35S::GUS transgenic plants. $\mathrm{Cq}$ and amplification efficiency values were processed using qBase software. Levels of uidA mRNAs were determined in flower buds $(F B)$, inflorescences $(I F)$, open flowers $(O F)$, siliques $(S L)$, roots $(R T)$, stems $(S T)$ and leaves $(L V)$. b The ratio of relative expression of cotton promoter/relative expression of the CaMV35S promoter

promoters were more specific and efficient than the CaMV35S in accumulating uidA transcripts in flower and fruit tissues. However, as expected, the constitutive promoter CaMV35S::GUS was capable of accumulating a greater amount of uidA transcripts in vegetative tissues such as the root, stem and leaves (Fig. 7a). For example, the relative expression of the $\mathrm{pGh} \beta \mathrm{Gal}$-like 1 promoter was at least 5fold, 16-fold, 19-fold and 4-fold higher than that of the CaMV35S promoter in flower buds, inflorescences, open flowers and siliques, respectively (Fig. 7b). The relative expression of uidA transcripts directed by the $\mathrm{pGhPl-like1} \mathrm{pro-}$ moter was 10.7-fold higher in flower buds and 7.5-fold higher in siliques than the CaMV35S promoter (Fig. 7b). Taking into account only the three fragments, the GhPME-likel gene promoter, the smaller p300_GhPME-like1::GUS fragment accumulated greater levels of uidA transcript in flower tissues.

Functional Analysis of Promoter Regions Using Transient Expression in Flower Buds of Gossypium hirsutum

To evaluate the functionality and specificity of the promoter regions isolated in this study, expression cassettes containing the five different promoters were used in transient expression, via biolistics, in 6-mm cotton flower buds (Fig. 8). All promoters directed GUS expression in stamens of cotton flower buds mirroring the expression pattern observed in qPCR experiments of cotton flower organs (Fig. 1d).

\section{Discussion}

Cotton is one of the most important crops cultivated worldwide although its production is hindered by several pests. Of these pests, the cotton boll weevil is the most important insect pest in Brazil - one of the top five producers and exportersand this pest is considered limiting in other countries. The boll weevil larva and adult feed on reproductive organs including stamens, ovules and fruit. If this insect is not contained, the damage to cotton fiber production can reach $75 \%$ (Martins et al. 2007b). Our major goal was to identify a promoter with high activity in reproductive tissues to fuse to genes encoding an insecticidal protein targeted against the insect-pest $A$. grandis. For this purpose, in our study, we evaluated the expression pattern of three ESTs derived from libraries of whole flowers in vegetative and reproductive tissues of cotton to identify genes expressed exclusively in $G$. hirsutum flowers, with the intention of isolating their promoter regions. These promoters, which were expressed predominantly in cotton flowers, may be useful for many applications in crop biotechnology where expression in reproductive tissues is required.

The genes selected in our search, which show accumulation of transcript in flower verticils and particularly in stamens, encode proteins from families that are highly expressed in the anther. A range of studies has shown that the pollen transcriptome is formed primarily by genes encoding hydrolytic enzymes that loosen and degrade the cell wall, such as pectate lyases, pectin methylesterase, polygalacturonase, glycosyl hydrolases and expansins (Becker et al. 2003; Haerizadeh et al. 2009). These genes are involved not only in the modification of the pollen tube cell wall of pollen grains but are also hydrolytic enzymes that may be important for penetration of flower stigmatic tissue (Jiang et al. 2005). The cotton GhPME-likel gene is highly expressed in stamens of flower buds primarily after the $6-\mathrm{mm}$ diameter stage when unicellular microspores are found in anthers (Fig. 1). The GhPME-like1 shows sequence similarity to the Arabidopsis pectin methylesterase genes (PME) AT4G15980 and $A T 5 G 49180$. These two genes show high and specific expression in the floral buds of Arabidopsis (Louvet et al. 2006; see supplementary Fig. S1a). Several studies suggest that PMEs are involved in the development and growth of the pollen tube and in the interaction with female tissues during fertilization (Jiang et al. 2005; Bosch et al. 2005; Tian et al. 2006). The expression pattern of cotton PME indicates that it may have a 
Fig. 8 Transient expression assays, via biolistics, in $G$. hirsutum flower buds. Histochemical assays of 6-mm cotton flower buds that had been bombarded with the tissue-specific promoters p300_GhPME-like1 (a), p760_GhPME-like1 (b), p1618 GhPME-like1 (c), pGh $\beta \bar{G}$ al-like1 (d) or pGhPllike1 (e). Es Stamen, $C a$ carpel, $O v$ ovary
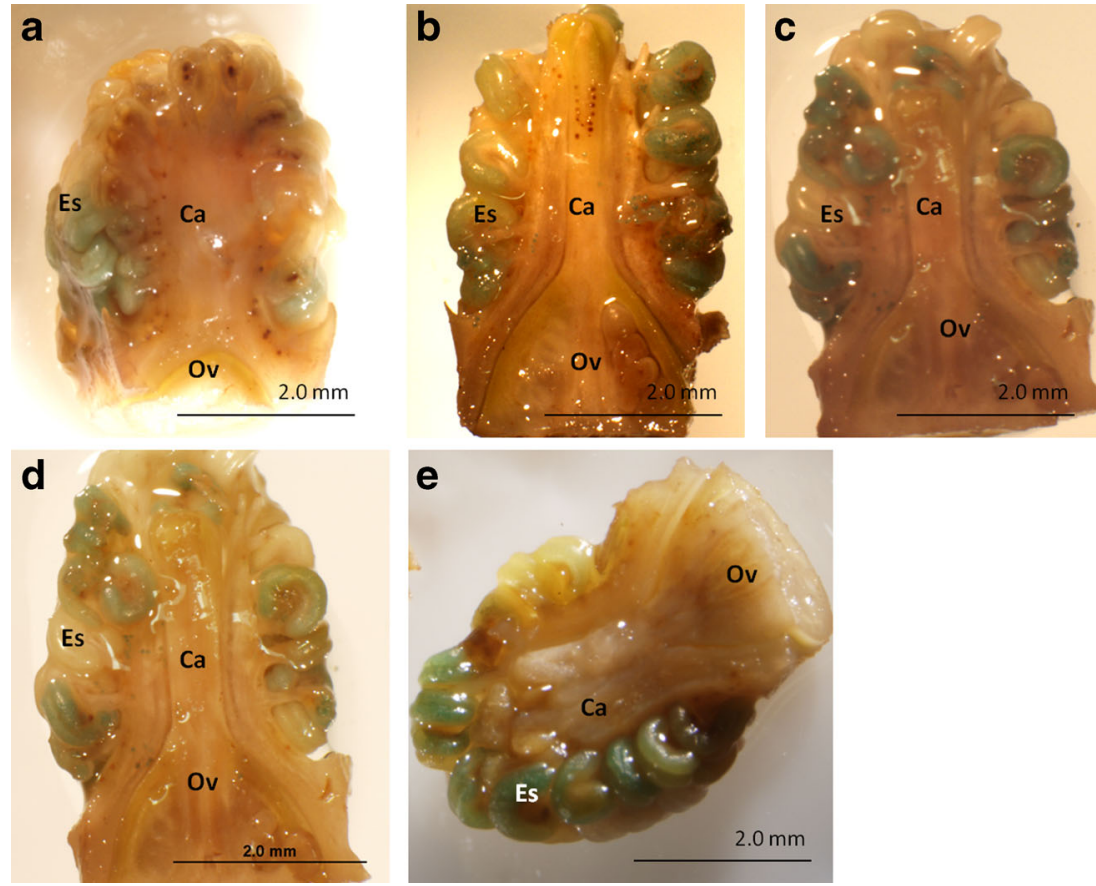

similar function to the putative Arabidopsis homologues. The Gh $\beta$ Gal-likel gene sequence shows high similarity to the $\beta$ galactosidase cotton GhGall expressed in flowers and fibers (Zhang and Liu 2005). The $\beta$-galactosidases (BGALs) belong to family 35 of glycosyl hydrolases that catalyze the hydrolysis of terminal b-galactosyl residues from carbohydrates, galactolipids, and glycoproteins. A previous study has shown that GhGall mRNA is abundant in flowers and in 5- to 10dpa fibers and declines in 20-dpa fibers; thus, it is involved in the early stages of development of cotton fiber (Zhang and Liu 2005). Our qPCR assays of the GhßGal-likel gene confirmed the temporal expression pattern in fruits (Fig. 1c). The GhßGal-likel gene sequence was also similar to BGAL sequences from Arabidopsis (BGAL 11, 13 and 14) that show high expression in mature pollen grains (Ahn et al. 2007; Hrubá et al. 2005; see supplementary Fig. S1b). In the case of the GhPL-like1 gene, qPCR results showed that the expression of this gene was flower-specific, primarily in stamens during the later stages of flower development (Fig. 1). The sequence of this gene shows high similarity to pectate lyaseslike (PLL) - enzymes that catalyze the eliminative cleavage of de-esterified pectin. This complex polysaccharide is a major component of the primary cell wall of many higher plants. There are 26 genes in the genome of Arabidopsis that encode pectate lyase (AtPLLs) proteins, the expression pattern of which vary considerably between different organs. Our phylogenetic analyses comparing the GhPL-likel gene sequence of $G$. hirsutum with PLL genes from Arabidopsis demonstrates a close relationship of GhPL-like1 with PLL 8 and 9 genes. These two genes, together with PLL 10 and 11, are flower-specific and show high expression in pollen grains (see supplementary Fig. S1c; Palusa et al. 2007). The putative flower-specific expression of the cotton genes GhPME-like1, GhßGal-likel and GhPL-likel and the previous reports on their putative Arabidopsis homologues encouraged us to isolate and characterize their respective promoter regions.

The cotton promoter fragments were qualitatively and quantitatively evaluated in Arabidopsis, the best heterologous system for dicotyledons. $A$. thaliana has been used extensively as a heterologous system to characterize promoter regions of dicot species (Koorneef and Meinke 2010; Zhao et al. 2012; Koia et al. 2013; Zhang et al. 2012). All cotton promoters evaluated in this study were found to show activity in various tissues and/or stages of flower and/or fruit development in Arabidopsis. Our data were obtained from transgenic lines grown from $\mathrm{T}_{3}$ seeds, demonstrating that constitutive expression was stable between generations. The $p G h P M E$-like1, $p G h \beta G a l-l i k e 1$ and $p G h P L$-likel promoters direct significantly higher levels of GUS expression in reproductive tissues and, in particular, in stamens, pollen grains and the inner layer of the anther wall; in endothecium cells; and in stigmatic cells, style and siliques. The expression pattern of the GhPME-like1, GhßGal-like1 and GhPLlike1 genes in cotton agrees in principal with the regulatory pattern of their promoters because lower activity was observed in vegetative tissues and much higher activity was observed in flower buds, inflorescences and open flowers. The $p G h P M E$-like1, $p G h \beta G a l$-like1 and $p G h P L$ like1 cotton promoters were compared with the uceA1.7 cotton promoter previously described by Viana et al. (2011), and they showed significantly higher activity in Arabidopsis reproductive organs (data not shown). 
PLACE, PlantCARE and Plant-PAN databases identified several cis-elements involved in expression in reproductive tissues in the promoter regions of the GhPME-like1, GhßGallikel and GhPL-likel genes that correlate with the expression pattern observed (see supplementary Fig. S2a, b and c). Various putative cis-acting regulatory elements required for pollen-specific expression or that are involved in enhancing gene expression in pollen were predicted. Among the putative cis regulatory elements found in the cotton promoters, the POLLEN1LELAT52 (AGAAA) cis-element was highly abundant. This element is repeated 14,4 or 3 times in the promoter regions of the GhPME-like1, GhßGal-likel and GhPL-likel gene, respectively. In tomato, it is responsible for coordinating and specifically activating pollen grain development (Bate and Twell 1998). The POLLEN1LELAT52 cis regulatory element was characterized as being required for specific pollen transcription via a series of deletions of the promoter regions of the lat52 gene (Bate and Twell 1998). There was also a significant number of copies of the ciselement GTGANTG10 (GTGA) in the cotton promoters. This cis-element is the binding site of transcription factors associated with late expression in pollen (Rogers et al. 2001). It is repeated five times, twice and once in pGhPME-like1, $\mathrm{p} G h \beta G$ al-like1 and $\mathrm{p} G h P L$-like1, respectively. The presence of pollen/anther-specific cis-elements in the different promoter fragments $p G h P M E$-like1, $p G h \beta G a l$-likel and $p G h P l$ likel suggest that they may be key factors in inducing strong anther and pollen promoter activity. Among the promoters evaluated, the $p G h P M E$-likel (300 bp) promoter showed the highest number of putative anther/pollen cis-elements comprising six POLLEN1LELAT52 and two GTGANTG10. This unique characteristic may underlie the fact that the $p G h P M E$ likel (300 bp) promoter showed the highest activity in reproductive tissues among the promoter fragments tested in this study, as demonstrated both by GUS activity analysis and the expression pattern of the uidA gene. Similar results were reported by Chen et al. (2012), who analyzed the Triticum aestivum PSG076 gene promoter and observed that the $0.4-\mathrm{kb}$ promoter fragment was capable of directing pollen-specific expression to a higher level than the longer promoter fragments. Similarly, Ni et al. (2008) observed that GUS activity levels and patterns directed by a $0.3-\mathrm{kb}$ promoter fragment (P-300) were almost identical to that of a $1.3-\mathrm{kb}$ promoter fragment (P-1301), indicating that P-300 contains all necessary elements for normal AtTSG1 expression. Similar results were reported by Zhao et al. (2012), who analyzed a seedabundant gene promoter from soybean. The two longer promoter fragments of the GhPME-likel gene (p760 GhPMElike1 and p1618_GhPME-like1) showed lower uidA expression in flower buds and inflorescences when compared with pGhPME-like1 (300 bp; Fig. 7a). In addition, the longer fragments were also active in other tissues, such as petals (Fig. 6). This petal expression may result from the activity of additional cis-elements present in the 760-bp and 1,618-bp fragments, such as the MYB.ph3 element (870 bp) and AP1CArGBox (1399, 1237, 875 and 741 bp). The GhßGal-like1 promoter also directed the highest level of uidA transcripts primarily in inflorescences and open flowers (Fig. 7a). Therefore, the $p G h P M E$-like1 (300 bp) and $p$ Gh $\beta$ Gal-like1 (356 bp) promoters may be the best choices when high expression is required in cotton reproductive organs. The uidA expression pattern driven by the GhPL-likel cotton promoter was similar to that observed by Sun and Nocker (2010) when they analyzed the promoters of the PLL8 and PLL9 genes in Arabidopsis. Therefore, in addition to their functional conservation, the expression of these genes may be regulated similarly. Moreover, transient expression analysis via biolistics in 6-mm cotton flower buds confirmed that GhPME-like1, GhßGal-likel and GhPL-likel promoters directed GUS expression primarily to stamens. Therefore, these promoters may be effective targeting sequences to increase foreign protein accumulation in transgenic cotton plants and for effective tissue-type-dependent expression.

Arabidopsis transgenic plants harboring cotton promoter constructs were compared with plants expressing the CaMV35S promoter - a well characterized constitutive promoter conferring strong transgene expression in dicot species. All cotton promoters tested showed higher activity and were more specific than CaMV35S in accumulating uidA transcripts in flower and fruit tissues (Figs. 5a, 7a). Similar results were reported by Dalal et al. (2010), who analyzed the constitutive CaMV35S promoter in tomato tissues and observed that this promoter drove lower GUS activity in flowers than in leaves. As expected, the CaMV35S promoter showed higher activity in vegetative tissues. Moreover, with regard to the lower expression in reproductive tissues compared with cotton promoters identified in this study, it has been shown that the commercial $B t$-cotton hybrids in India that use CaMV35S express less than the critical levels of Cry1 Ac required for full protection against the bollworm $H$. armigera (Kranthi et al. 2005). The activity of CaMV35S decreases during cotton plant development, particularly in some plant organs, including the boll rind, square bract, bud and flower, which is the main feeding site for bollworm larvae (Kranthi et al. 2005). Therefore, the CaMV35S promoter has proved a poor choice for $B t$-transgenic technology for efficient and sustainable protection from pests that attack reproductive tissue in cotton (Kranthi et al. 2005). Taking this information into account, the novel promoters that are expressed predominantly in flower and/or fruit characterized in this study may be key tools for enhancing expression of toxin genes in reproductive tissues.

In summary, five different fragments of promoters of three different cotton genes were assessed in transgenic Arabidopsis plants throughout various stages of reproductive and vegetative tissue development. These promoters were found to be active in the Arabidopsis plants, including in the 
flower, stamens and pollen grains, and showed distinct activity patterns. The activity of the promoters was also confirmed by transient expression assays in flower buds of $G$. hirsutum. Due to their high activity in reproductive tissues and their short size, the novel cotton promoters identified by our study may represent an important tool in the generation of crop plants resistant to insect pests such as the cotton boll weevil and bollworm, which damage plants during the reproductive stage.

Acknowledgments We thank the researchers, Fernando Campos de Assis Fonseca and Raquel Sampaio, from Embrapa Genetic Resources and Biotechnology technical assistance with biolistic experiment in cotton. This work was part of S.A's PhD research in Genetics, at the Department of Genetics of the Universidade Federal do Rio de Janeiro (UFRJ), and was supported by Conselho Nacional de Desenvolvimento Científico e Tecnológico (CNPq; M. Alves-Ferreira: \# 306025/2010-8) and Fundação de Amparo à Pesquisa do Rio de Janeiro (FAPERJ).

\section{References}

Ahn YO, Zheng M, Bevan DR, Esen A, Shiu SH, Peng HP, Miller JT, Cheng LI, Poulton JE, Shih MC (2007) Functional genomics analysis of Arabidopsis thaliana glycoside hydrolase family 35 . Phytochemistry 11:1510-1520

Altschul SF, Madden TL, Schaffer AA, Zhang JH, Zhang Z, Miller W, Lipman DJ (1997) Gapped BLAST and PSI-BLAST: a new generation of protein database search programs. Nucleic Acids Res 25: 3389-3402

Artico S, Nardeli SM, Oliveira-Neto OB, Grossi-de-Sa MF, AlvesFerreira M (2010) Identification and evaluation of new reference genes in Gossypium hirsutum for accurate normalization of realtime quantitative RT-PCR data. BMC Plant Biol 10:12-22

Bate N, Twell D (1998) Functional architecture of a late pollen promoter: pollen-specific transcription is developmentally regulated by multiple stage-specific and co-dependent activator elements. Plant Mol Biol 37:859-869

Baum JA, Bogaert T, Clinton W, Heck GR, Feldmann P, Ilagan O, Johnson S, Plaetinck G, Munyikwa T, Pleau M (2007) Control of coleopteran insect pests through RNA interference. Nat Biotechnol 25:1322-1326

Becker JD, Boavida LC, Carneiro J, Haury M, Feijo JA (2003) Transcriptional profiling of Arabidopsis tissues reveals the unique characteristics of the pollen transcriptome. Plant Physiol 133:713 725

Bosch M, Cheung AY, Hepler PK (2005) Pectin methylesterase, a regulator of pollen tube growth. Plant Physiol 138:1334-1346

Bradford MM (1976) A rapid and sensitive method for the quantitation of microgram quantities of protein utilizing the principle of protein-dye binding. Anal Biochem 72:248-254

Chang WC, Lee TY, Huang HD, Huang HY, Pan RL (2008) PlantPAN: plant promoter analysis navigator, for identifying combinatorial cisregulatory elements with distance constraint in plant gene groups. BMC Genomics 9:561

Chen L, Miao Y, Wang C, Su P, Li T, Wang R, Hao X, Yang G, He G, Gao C (2012) Characterization of a novel pollen-specific promoter from wheat (Triticum Aestivum L.). Plant Mol Biol Rep 30:1426-1432

Chitkowski RL, Turnipseed SG, Sullivan MJ, Bridges WC (2003) Field and laboratory evaluations of transgenic cottons expressing one or two Bacillus thuringiensis var. kurstaki Berliner proteins for management of noctuid (Lepidoptera) pests. J Econ Entomol 96: $755-762$

Christensen AH, Quail PH (1996) Ubiquitin promoter based vectors for high-level expression of selectable and/or screenable marker genes in monocotyledonous plants. Transgenic Res 5:213-218.

Clough SJ, Bent AF (1998) Floral dip: a simplified method for agrobacterium-mediated transformation of Arabidopsis thaliana. Plant J 16:735-743

Czechowski TSM, Altmann T, Udvardi MK, Scheible WR (2005) Genome-wide identification and testing of superior reference genes for transcript normalization in Arabidopsis. Plant Physiol 139:5-17

Dalal M, Chinnusamy V, Bansal KC (2010) Isolation and functional characterization of lycopene $\beta$-cyclase (CYC-B) promoter from Solanum habrochaites. BMC Plant Biol 10:61

Desfeux C, Clough SJ, Bent AF (2000) Female reproductive tissues are the primary target of agrobacterium-mediated transformation by the arabidopsis floral-dip method. Plant Physiol 123:895-904

Fang RX, Nagy F, Sivasubramaniam S, Chua NH (1989) Multiple cis regulatory elements for maximal expression of the cauliflower mosaic virus $35 \mathrm{~S}$ promoter in transgenic plants. Plant Cell 1:141-150

Finn RD, Mistry J, Schuster-Bockler B, Griffiths-Jones S, Hollich V (2006) Pfam: clans, web tools and services. Nucleic Acids Res 34: D247-D251

Greenberg SM, Sappington TW, Setamou M, Coleman RJ (2003) Influence of different cotton fruit sizes on boll weevil (Coleoptera: Curculionidae) oviposition and survival to adulthood. Environ Entomol 33:443-449

Grossi-de-Sa MF, Magalhães MQ, Silva MS, Silva SMB, Dias SC, Nakasu EYT, Brunetta PSF, Oliveira GR, Oliveira Neto OB, Oliveira RS, Soares LHB, Ayub MAZ, Siqueira HAA, Figueira ELZ (2007) Susceptibility of Anthonomus grandis (cotton boll weevil) and Spodoptera frugiperda (fall armyworm) to a Cry1Iatype toxin from a Brazilian Bacillus thuringiensis strain J. J Biochem Mol Biol 40:773-782

Guilley H, Dudley RK, Jonard G, Balazs E, Richards KE (1982) Transcription of cauliflower mosaic virus DNA: detection of promoter sequences, and characterization of transcripts. Cell 30:763770

Guindon S, Dufayard JF, Lefort V, Anisimova M, Hordijk W, Gascuel O (2010) New algorithms and methods to estimate maximumlikelihood phylogenies: assessing the performance of PhyML 3.0. Syst Biol 3:307-321

Haerizadeh F, Wong CE, Bhalla PL, Gresshoff PM, Singh MB (2009) Genomic expression profiling of mature soybean (Glycine max) pollen. BMC Plant Biol 9:25

Haynes JW, Smith JW (1992) Longevity of laboratory-reared boll weevils (Coleoptera: Curculionidae) offered honey bee-collected pollen and plants unrelated to cotton. J Entomol Sci 27:366-374

Higo K, Ugawa Y, Iwamoto M, Korenaga T (1999) Plant cis-acting regulatory DNA elements (PLACE) database: 1999. Nucleic Acids Res 27:297-300

Hrubá P, Honys D, Twell D, Capková V, Tupý J (2005) Expression of $\beta$ galactosidase and $\beta$-xylosidase genes during microspore and pollen development. Planta 220:931-940

Jefferson R (1987) Assaying chimeric genes in plants: the GUS gene fusion system. Plant Mol Biol Report 5:387-405

Jiang L, Yang S, Xie LF, Puah CS, Zhang XQ, Yang WC, Sundaresan VYED (2005) VANGUARD1 encodes a pectin methylesterase that enhances pollen tube growth in the Arabidopsis style and transmitting tract. Plant Cell 17:584-596

Koia J, Moyle R, Hendry C, Lim L, Botella JR (2013) Pineapple translation factor SUI1 and ribosomal protein L36 promoters drive constitutive transgene expression patterns in Arabidopsis thaliana. Plant Mol Biol 81:327-336

Koorneef M, Meinke D (2010) The development of Arabidopsis as a model plant. Plant J 61:909-921 
Kranthi KR, Naidu S, Dhawad CS, Tatwawadi A, Mate K, Patil E, Bharose AA, Behere GT, Wadaskar RM, Kranthi S (2005) Temporal and intra-plant variability of Cry1Ac expression in Btcotton and its influence on the survival of the cotton bollworm, Helicoverpa armigera (Hubner) (Noctuidae : Lepidoptera). Curr Sci 89:291-298

Larkin MA, Blackshields G, Brown NP, Chenna R, McGettigan PA, McWilliam H, Valentin F, Wallace IM, Wilm A, Lopez R, Thompson JD, Gibson TJ, Higgins DJ (2007) Clustal W and clustal $X$ version 2.0. Bioinformatics 23:2947-2948

Lescot M, Dehais P, Thijs G, Marchal K, Moreau Y, Van de Peer Y, Rouze P, Rombauts S (2002) PlantCARE, a database of plant cis-acting regulatory elements and a portal to tools for in silico analysis of promoter sequences. Nucleic Acids Res 30:325-327

Liang YS, Jeon YA, Lim SH, Kim JK, Lee JY, Kim YM, Lee YH, Ha SH (2011) Vascular-specific activity of the Arabidopsis carotenoid cleavage dioxygenase 7 gene promoter. Plant Cell Rep 6:973-980

Louvet R, Cavel E, Gutierrez L, Guénin S, Roger D, Gillet F, Guerinea F, Pelloux J (2006) Comprehensive expression profiling of the pectin methylesterase gene family during silique development in Arabidopsis thaliana. Planta 224:782-791

Mao YB, Cai WJ, Wang JW, Hong GJ, Tao XY, Wang LJ, Huang YP, Chen XY (2007) Silencing a cotton bollworm P450 monoxygenase gene by plant-mediated RNAi impairs larval tolerance of gossypol. Nat Biotechnol 25:1307-1313

Martins WFS, Ayres CFJ, Lucena WA (2007a) Genetic diversity of Brazilian naturalpopulations of Anthonomus grandis Boheman(Coleoptera: Curculionidae), the major cottonpest in the New World. Genet Mol Res 6:23-32

Martins ES, Praça LB, Dumas VF, Silva-Werneck JO, Sone EH, Waga IC, Berry C, Monnerat RG (2007b) Characterization of Bacillus thuringiensis isolates toxic to cotton boll weevil (Anthonomus grandis). Biol Control 40:65-68

Ni SM, Meng LJ, Zhao J, Wang XC, Chen J (2008) Isolation and characterization of the trichome-specific AtTSG1 promoter from Arabidopsis thaliana. Plant Mol Biol Rep 26:263-276. doi:10. 1007/s11105-008-0036-5

Odell JT, Nagy F, Chua NH (1985) Identification of DNA sequences required for activity of the cauliflower mosaic virus $35 \mathrm{~S}$ promoter. Nature 313:810-812

Olsen KM, Daly JC, Finnegan EJ, Mahon RJ (2005) Changes in CrylAc $\mathrm{Bt}$ transgenic cotton in response to two environmental factors: temperature and insect damage. J Econ Entomol 98:1382-1390

Onãte-Sánchez L, Vicente-Carbajosa J (2008) DNA-free RNA isolation protocols for Arabidopsis thaliana, including seeds and siliques. BMC Res Notes 1:840-860

Palusa SG, Golovkin M, Shin SB, Richardson DN, Reddy ASN (2007) Organ-specific, developmental, hormonal and stress regulation of expression of putative pectate lyase genes in Arabidopsis. New Phytol 174:537-550

Potenza C, Aleman L, Gopalan CS (2004) Targeting transgene expression in research, agricultural, and environmental applications: promoters used in plant transformation. In Vitro Cell Dev Biol Plant 40:1-22

Prestridge DS (1991) SIGNAL SCAN: a computer program that scans DNA sequences for eukaryotic transcriptional elements. Comput Appl Biosci 7:203-206

Rech EL, Vianna GR, Aragao FL (2008) High-efficiency transformation by biolistics of soybean, common bean and cotton transgenic plants. Nat Protoc 3:410

Rocha PSCF, Sheikh M, Melchiorre R, Fagard M, Boutet S, Loach R, Moffatt B, Wagner C, Vaucheret H, Furner I (2005) The Arabidopsis homology-dependent gene silencing gene codes for an S-adenosyl-L-homocysteine hydrolase required for DNA methylation-dependent gene silencing. Plant Cell 17:404-417

Rogers HJ, Bate N, Combe J, Sullivan J, Sweetman J, Swan C, Lonsdale DM, Twell D (2001) Functional analysis of cis-regulatory elements within the promoter of the tobacco late pollen gene $g 10$. Plant Mol Biol 45:577-585

Rozen S and Skaletsky HJ (2002) Primer3 on the www for general users and for biologist programmers. In: Misener S, Krawetz SA (eds) Bioinformatics methods and protocols: methods in molecular biology. Humana, Totowa, NJ, pp 365-386. Source code available at http://fokker.wi.mit.edu/primer3/

Saitou N, Nei M (1987) The neighbor-joining method - a new method for reconstructin phylogenetic trees. Mol Biol Evol 4:406-425

Sanahuja G, Banakar R, Twyman RM, Capell T, Christou P (2011) Bacillus thurigiensis: a century of research, development and commercial applications. Plant Biotechnol J 9:283-300

Schenk PM, Remans T, Sagi L, Elliott AR, Dietzgen RG, Swennen R, Ebert PR, Grof CPL, Manners JM (2001) Promoters for pregenomic RNA of banana streak badnavirus are active for transgene expression in monocot and dicot plants. Plant Mol Biol 47:399-412

Sun L, Nocker SV (2010) Analysis of promoter activity of members of the PECTATE LYASE-LIKE (PLL) gene family in cell separation in Arabidopsis. BMC Plant Biol 1:152

Sunilkumar G, Mohr L, Lopata-Finch E, Emani C, Rathore KS (2002) Developmental and tissue-specific expression of CaMV 35S promoter in cotton as revealed by GFP. Plant Mol Biol 50:463-474

Tamura K, Peterson D, Stecher G, Nei M, Kumar S (2011) MEGA5: molecular evolutionary genetics analysis using maximum likelihood, evolutionary distance, and maximum parsimony methods. Mol Biol Evol 10:2731-2739

Tian GW, Chen MH, Zaltsman A, Citovsky V (2006) Pollen-specific pectin methylesterase involved in pollen tube growth. Dev Biol 294:83-91

Udall JA, Swanson JM, Haller K, Rapp RA, Sparks ME, Hatfield J, Yu YS, Wu YR, Dowd C, Arpat AB, Sickler BA, Wilkins TA, Guo JY, Chen XY, Scheffler J, Taliercio E, Turley R, Mcfadden H, Payton P, Klueva N, Allen R, Zhang DS, Haigler C, Wilkerson C, Suo JF, Schulze SR, Pierce ML, Essenberg M, Kim H, Llewellyn DJ, Dennis ES, Kudrna D, Wing R, Paterson AH, Soderlund C, Wendel JF (2006) A global assembly of cotton ESTs. Genome Res 16:441-450

Viana AAB, Fragoso RR, Guimarães LM, Pontes N, Oliveira-Neto OB, Artico S, Nardeli SM, Alves-Ferreira M, Batista JN, Silva MCM, Grossi-de-Sa MF (2011) Isolation and functional characterization of a cotton ubiquitination-related promoter and $5^{\prime} \mathrm{UTR}$ that drives high levels of expression in root and flower tissues. BMC Biotechnol 11:115

Whelan S, Goldman N (2001) A general empirical model of protein evolution derived from multiple protein families using a maximum-likelihood approach. Mol Biol Evol 5:691-699

Yamagata H, Yonesu K, Hirata A, Aizono Y (2002) TGTCACA motif is a novel $c i s$-regulatory enhancer element involved in fruit-specific expression of the cucumisin gene. J Biol Chem 277:11582-11590

Yi N, Kim YS, Jeong MH, Oh SJ, Jeong JS, Park SH, Jung H, Choi YD, Kim JK (2010) Functional analysis of six drought-inducible promoters in transgenic rice plant throughout all stages of plant growth. Planta 232:743-754

Zhang HM, Liu JY (2005) Molecular cloning characterization of a $\beta$ Galactosidade gene expression preferentially in cotton fibers. J Integr Plant Biol 47:223-232

Zhang W, McElroy D, Wu R (1991) Analysis of rice Act1 5' region activity in transgenic rice plants. Plant Cell 3:1155-1165

Zhang X, Hu Y, Jiang C, Zhang W, Li Z, Ming F (2012) Isolation of the Chinese rose sHSP gene promoter and its differential regulation analysis in transgenic Arabidopsis plants. Mol Biol Rep 39:1145-1151

Zhao S, Fernald RD (2005) Comprehensive algorithm for quantitative real-time polymerase chain reaction. J Comput Biol 12:1047-1064

Zhao Y, Shao S, Li X, Zhai Y, Zhang Q, Qian D, Wang Q (2012) Isolation and activity analysis of a seed-abundant soyAP1 gene promoter from soybean. Plant Mol Biol Rep 30:1400-1407

Zimmermann P, Hirsch-Hoffmann M, Hennig L, Gruissem W (2004) Genevestigator Arabidopsis microarray database and analysis toolbox. Plant Physiol 136:2621-2632 